\title{
Sistem Informasi Kartu Hasil Studi (KHS) Online Pada Politeknik Sains \& Teknologi Wiratama Maluku Utara
}

\author{
Darman Umagapi ${ }^{1}$, Yuslinah Nurdiyani ${ }^{2}$ \\ Program Studi Manajemen Informatika ${ }^{1}$, Program Studi Teknik komputer ${ }^{2}$ \\ Politeknik Sains dan Teknologi Wiratama Maluku Utara \\ umagapi01@yahoo.com
}

\begin{abstract}
Abstrak
Politeknik Wiratama dalam pengambilan KHS masih bersifat konvensional. Biro Akademik juga masih mengalami banyak masalah diantaranya, yaitu pada waktu pencetakan Kartu Hasil Studi (KHS). Penelitian ini bertujuan untuk membuat suatu sistem informasi kartu hasil studi yang di bangun menggunakan bahasa pemrograman PHP dan menggunakan database $M y S Q L$. Dalam penelitian ini, penulis menerapkan beberapa metode, diantaranya analisis, perancangan, uji coba menggunakan Black Box testing dan implementasi. Hasil penelitian ini adalah sistem informasi kartu hasil studi online yang dapat memudahkan mahasiswa dalam pengambilan kartu hasil studi dan mempermudah dosen dan admin dalam pengolahan data nilai mahasiswa. Sehingga proses pengambilan kartu hasil studi lebih efektif dan efisien. Dengan begitu mahasiswa dapat dengan mudah mengakses informasi tentang nilai hasil belajarnya darimana saja dan kapan saja dengan menggunakan fasilitas Internet.
\end{abstract}

\section{Kata Kunci: Sistem, Informasi, Kartu Hasil Studi (KHS), Online}

\section{Abstract}

Politeknik Wiratama in intake of KHS still have the character of conventionally. Bureau of Akademik also still experience of many problem among others, that is when printing of Card Result Of Study (KHS). This Research to make an card information system result of study which in awaking up to use mechine Ianguage of PHP and use database of MySQL. In this research, writer apply some method, among others analyse, scheme, test-drive use testing Black Box and Implementation. Result of this research card information system result of study of online able to facilitate student in intake of card result of study and water down and lecturer of admin in data processing assess student. So that process intake of card result of study more effective and is efficient. That way student earn easily access information about value result of learning of just where from and any time by using facility of Internet.

Keywords: Information System, Card Study Results, Online

\section{PENDAHULUAN}

Perkembangan teknologi internet yang pesat telah memacu munculnya berbagai aplikasi baru termasuk di bidang teknologi informasi. Dengan perkembangan teknologi dan informasi, hampir data-data penting atau informasiinformasi penting disimpan dan didistribusikan kepada pengguna melalui alat yang namanya komputer, sampai saat ini teknologi yang banyak digunakan oleh pengguna informasi adalah dengan internet (Taufiq, 2013). Media Online adalah salah satu revolusi di bidang informasi berbasis teknologi internet.

Akreditasi lembaga pendidikan kini mulai melirik kemajuan teknologi IT (Information Technology) yang ada. Sebuah lembaga pendidikan dapat dinilai kualitasnya dari teknologi yang digunakan (Nur Asih,2013). 
Kampus Politeknik Sains \& Teknologi Wiratama Maluku Utara merupakan salah satu dari PTS (Perguruan Tinggi Swasta) yang terdapat di Kota Ternate, pada Politeknik Wiratama dalam pengambilan kartu hasil studi (KHS) masih bersifat konvensional, pengelolaan data kartu hasil studi (KHS) dan Transkrip Nilai pada saat ini sudah terkomputerisasi, namun belum bisa diakses secara online.

Penerapan sistem informasi kartu hasil studi online pada Politeknik Wiratama perlu diperhatikan, karena dengan menerapkan sistem informasi KHS online maka lembaga akan lebih mudah untuk mengelola data dan memberikan pelayanan KHS kepada mahasiswa, begitu juga sebaliknya mahasiswa akan mudah untuk mengakses KHS secara online.

Berdasarkan hasil uraian di atas maka peneliti berinisatif untuk membuat sebuah program aplikasi dengan judul "Sistem Informasi Kartu Hasil Studi (Khs) Online Pada Politeknik Sains \& Teknologi Wiratama Maluku Utara".

\section{Rumusan Masalah}

Berdasarkan latar belakang diatas, maka dapat diidentifikasikan permasahannya, yaitu bagaimana merancang sistem informasi kartu hasil studi (KHS) online pada Politeknik Sains \& Teknologi Wiratama Maluku Utara?

\section{Tujuan Penelitian}

Adapun tujuan penelitian ini adalah untuk merancang sistem informasi kartu hasil studi (KHS) online pada Politeknik Sains \& Teknologi Wiratama Maluku Utara dan membuat kartu hasil studi (KHS) yang fleksibel (lebih mudah), agar bisa diakses oleh mahasiswa

\section{Manfaat Penelitian}

Sistem yang baru diharapkan dapat memperbaharui sistem yang lama, sehingga mampu menyediakan informasi yang akurat dan cepat kepada mahasiswa. Mempermudah mahasiswa memperoleh layanan kartu hasil studi (KHS). Serta mempermudah admin dalam pengolahan data kartu hasil studi (KHS).

\section{Tinjauan Pustaka}

Penelitian yang dilakukan oleh Jalaludin Asep (2010) yang berjudul Perancangan Sistem informasi dan Kemahasiswaan (SIAK) Versi 1.0 Menggunakan Visual Foxpro 6.0 Di Akademi Manajemen Informatika dan Komputer (AMIK) Wahana Mandiri Tanggerang. Tujuan penelitian ini diharapkan dapat menghasilkan sistem informasi akademik dan kemahasiswaan (SIAK) versi 1.0 menggunakan visual foxpro 6.0 agar dapat memudahkan pelayanan bagi mahasiswa khususnya dalam pengisian KRS, pencetakan dan pengambilan Kartu Ujian, KHS (Kartu Hasil Studi) maupun Transkrip Nilai (Daftar Prestasi Akademik). Hasil penelitian adalah membantu mengurangi antrian yang ada di front office (petugas BAAK) pada saat pengisian KRS dan pada saat melihat KHS atau Transkrip nilai (Daftar Prestasi Akademik) karena bisa dilakukan di komputer (client-user) yang sudah disediakan. Penelitian menggunakan Aplikasi Visual Foxpro 6.0 dan belum ada pemanfaatan jaringan dan pelatihan bagi pengguna sistem.

Penelitian yang dilakukan oleh Ari Zusnan Fak hrudin dan Eko Purwanto (2012) yang berjudul Sistem Informasi Kartu Rencana Studi dan Kartu Hasil studi Online studi (kasus pada STMIK Duta Bangsa Surakarta). Tujuan penelitian ini 
bertujuan agar mahasiswa bisa mengisi KRS secara online dan dosen bisa memberikan nilai KHS secara online sesuai mata kuliah yang diambil oleh mahasiswa. Hasil penelitian adalah agar mahasiswa dapat mengisi KRS secara online dan dosen memberikan nilai KHS secara online kepada mahasiswa. Hasil akhir dari implementasi sistem KRS dan KHS online adalah laporan yang terdiri dari laporan data dosen, data mata kuliah, data mahasiswa, data mengajar, KHS, transkip, kartu ujian, daftar nilai, presensi mata kuliah, presensi ujian dan laporan pembelajan. Diharapkan dengan adanya laporan-laporan tersebut akan memudahkan pihak STAIMUS Surakarta dalam mengelola KRS dan KHS.

\section{LANDASAN TEORI \\ Pengertian Sistem}

Selanjutnya, McLeod mendefiniskan sistem adalah sekelompok elemen-elemen yang terintegrasi dengan tujuan yang sama untuk mencapai tujuan. Sistem juga merupakan suatu jaringan kerja dari prosedur-prosedur yang saling berhubungan, terkumpul bersama-sama untuk melakukan suatu kegiatan atau untuk tujuan tertentu (Yakub, 2012).

Berdasarkan defenisi tersebut maka dapat disimpulkan, sistem merupakan kumpulan dari beberapa himpunan elemen-elemen yang saling berinteraksi, memiliki keterkaitan dan saling bekerja sama serta membentuk suatu kesatuan untuk mencapai suatu tujuan atau sasaran tertentu.

\section{Karakteristik Sistem}

Jogiyanto (2013) mengatakan bahwa suatu sistem mempunyai karakterisktik atau sifat-sifat tertentu, yaitu mempunyai komponen-komponen (components), batasan sistem (boundary), lingkungan luar sistem (environments), penghubung (interface), masukan (input), keluaran (output), pengolah (process), dan sasaran (objectives).

\section{Pengertian Sistem}

Menurut Hartono (2013) informasi pada dasarnya adalah sehimpunan data yang telah diolah menjadi suatu yang memiliki arti dan kegunaan yang lebih luas. Kualitas informasi (quality of information) harus dapat memenuhi beberapa yaitu: akurat, relevan dan tepat waktu

\section{Pengertian Sistem Informasi}

Menurut O'Brian, sistem informasi (information system) merupakan kombinasi teratur dari orang-orang, perangkat keras, perangkat lunak, jaringan komunikasi, dan sumber daya data yang mengumpulkan, mengubah, menyebarkan informasi dalam sebuah organisasi. (Yakub, 2012).

\section{Pengertian KHS}

Kartu Hasil Studi (KHS) adalah kartu yang menunjukkan nilai dan prestasi mahasiswa pada semester tertentu (Anonimouse, 2012). Adapun fungsi kartu hasil studi (KHS) adalah sebagai berikut:

1. Memberikan landasan untuk menilai hasil usaha (prestasi) yang telah dicapai oleh peserta didik.

2. Memberikan informasi yang sangat berguna, guna mengetahui posisi masing-masing peserta didik di tengah-tengah kelompoknya.

3. Memberikan bahan yang penting untuk memilih dan kemudian menetapakan status peserta didik.

\section{Pengertian DFD}


Sutabri (2012) Data Flow Diagram adalah suatu network yang menggambarkan suatu system automa atau komputerisasi, manualisasi, atau gabungan dari keduanya, yang penggambaranya disusun dalam bentuk kumpulan komponen sitem yang saling berhubungan sesuai aturan mainnya. Keuntungan penggunaan $D F D$ adalah memungkinkan untuk menggambarkan sistem dari level yang paling tinggi kemudian menguraikannya menjadi level yang lebih rendah (dekomposisi). Sedangkan kekurangan penggunaan $D F D$ adalah tidak menunjukkan proses pengulangan (looping), proses keputusan dan proses perhitungan.

\section{ERD}

Menurut Brady dan Loonam (2010), dalam bahasa indonesia bahwa Entity Relationship diagram (ERD) merupakan teknik yang digunakan untuk memodelkan kebutuhan data dari suatu organisasi, biasanya oleh System Analys dalam tahap analisis persyaratan proyek pengembangan system. Sementara seolah-olah teknik diagram atau alat peraga memberikan dasar untuk desain database relasional

\section{PHP}

PHP adalah singkatan dari "PHP: Hypertext Prepocessor", yaitu bahasa pemrograman yang digunakan secara luas untuk penanganan pembuatan dan pengembangan sebuah situs web dan bisa digunakan bersamaan dengan HTML. PHP diciptakan oleh Rasmus Lerdorf pertama kali tahun 1994. Pada awalnya PHP adalah singkatan dari "Personal Home Page Tools". Selanjutnya diganti menjadi FI ("Forms Interpreter"). Sejak versi 3.0, nama bahasa ini diubah menjadi "PHP: Hypertext Prepocessor" dengan singkatannya "PHP". PHP versi terbaru adalah versi ke-5. Berdasarkan survey Netcraft pada bulan Desember 1999, lebih dari sejuta site menggunakan PHP, di antaranya adalah NASA, Mitsubishi, dan RedHat.

\section{MySQL}

$M y S Q L$ adalah sebuah perangkat lunak sistem manajemen basis data $S Q L$ (database management system) atau DBMS yang multithread, multiuser,dengan sekitar 6 juta instalasi di seluruh dunia. MySQL AB membuat $M y S Q L$ tersedia sebagai perangkat lunak gratis dibawah lisensi GNU General Public License (GPL), tetapi mereka juga menjual dibawah lisensi komersial untuk kasus-kasus dimana penggunaannya tidak cocok dengan penggunaan $G P L$

\section{XAMPP}

Pengertian XAMPP adalah perangkat lunak (free software) bebas, yang mendukung untuk banyak sistem operasi, yang merupakan kompilasi dari beberapa program. Fungsi XAMPP sendiri adalah sebagai server yang berdiri sendiri (localhost), yang terdiri beberapa program antara lain: Apache HTTP Server, MySQL database, dan penerjemah bahasa yang ditulis dengan bahasa pemrograman PHP danPerl. Nama XAMPP sendiri merupakan singkatan dari $\mathrm{X}$ (empat sistem operasi apapun), Apache, MySQL, PHP.

\section{METODE PENELITIAN}

\section{Lokasi dan Waktu Penilitian}

Peneliti memilih objek dari penelitian itu sendiri yaitu pada Kampus Politeknik Sains \& Teknologi Wiratama Maluku Utara Ternate yang beralamat di Jati Jln. Jati Trans Kota Ternate Selatan. 


\section{Metode Pengumpulan Data}

Metode pengumpulan data yang digunakan dalam penelitian ini adalah dokumentasi dan wawancara.

\section{Dokumentasi}

Menurut Sugiyono (2013:240) dokumen merupakan catatan peristiwa yang sudah berlalu. Dokumen bisa berbentuk tulisan, gambar, atau karyakarya monumental dari seorang. Dokumen yang berbentuk tulisan misalnya catatan harian, sejarah kehidupan (life histories), ceritera, biografi, peraturan, kebijakan. Dokumen yang berbentuk gambar misalnya foto, gambar hidup, sketsa dan lain-lain. Dokumen yang berbentuk karya misalnya karya seni, yang dapat berupa gambar, patung, film dan lain-lain. Studi dokumen merupakan pelengkap dari penggunaan metode observasi dan wawancara dalam penelitian kualitatif..

\section{Wawancara}

Menurut Esterberg dalam Sugiyono (2013:231) wawancara merupakan pertemuan dua orang untuk bertukar informasi dan ide melalui tanya jawab, sehingga dapat dikontruksikan makna dalam suatu topik tertentu.

\section{Studi Kepustakaan}

Dengan mencari dan mengumpulkan data yang diperlukan dari berbagai bukubuku, catatan-catatan, dan gambar-gambar yang menunjang penyusunan laporan tugas akhir ini.

\section{ANALISIS DAN PERANCANGAN}

Sistem yang berjalan pada kampus Politeknik Sains \&Teknologi Wiratama Maluku Utara dapat dideskripsikan sebagai berikut: Diawali dengan dosen memasukkan nilai ke biro akademik, kemudian biro akan mengecek dan memverifikasi semua nilai mahasiswa, apabila semua nilai sudah terverivikasi biro melakukan input dan menghitung nilai mahasiswa pada setiap mata kuliahnya, setalah data nilai terinput biro akan melakukan cetak data KHS dan memberikan pada mahasiswa

Dari permasalahan yang sudah teridentifikasi pada sistem yang sedang berjalan maka peneliti mengusulkan sebuah sistem yang dihaarapkan akan memudahkan pelayanan pada administrator, prodi, dosen maupun mahasiswa. Sistem yang akan di usulkan adalah sebagai berikut

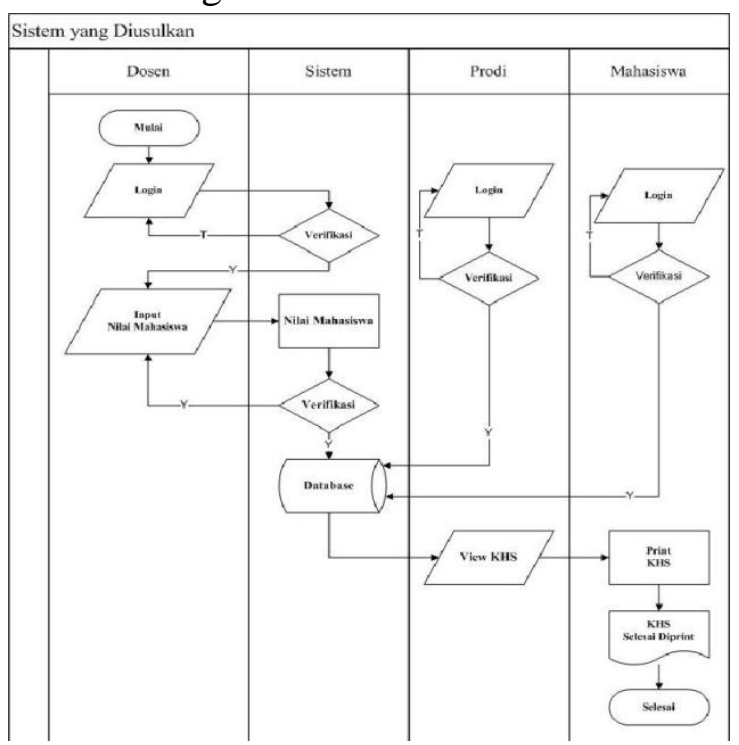

Gambar 1. Analisis Sistem yang diusulkan

\section{Kebutuhan Perangkat}

Perangkat Keras (Hardware) dengan spesifikasi yaitu:

1. Laptop Axioo-PC

2. Procesor Intel $(\mathrm{R}) \mathrm{Atom}^{\mathrm{TM}} \mathrm{CPU} \mathrm{N} 570$ @ $1.666 \mathrm{GHz}$

3. RAM 2, $00 \mathrm{~GB}$

4. Hardisk $160 \mathrm{~GB}$

5. Printer Canon IP2870S

Perangkat Lunak Alat yang digunanakan dalam penelitan ini berupa perangkat lunak (Software). 
1. Windows 7 Ultimate sebagai System Operasi

2. Ms.Access 2007 sebagai Pengelola Database

3. Program web: XAMPP, MySQL, PHP dan $H T M L$.

4. Microsoft Visio 2007

\section{Rancangan Tabel}

Tabel 1 Tabel dosen

\begin{tabular}{l|l|c|c}
\hline Field & Type & size & PrimaryKey \\
\hline NIDN & Integer & 11 & $*$ \\
\hline Nama_Dosen & Varchar & 50 & \\
\hline JK & Char & 1 & \\
\hline Pend_Terakhir & Varchar & 50 & \\
\hline Alamat & Text & 100 & \\
\hline No_hp & Varhar & 30 & \\
\hline
\end{tabular}

Tabel 2. Tabel Mata Kuliah

\begin{tabular}{l|c|c|c|}
\hline \multicolumn{1}{c|}{ Field } & Type & Size & PrimaryKey \\
\hline Kode_Matkul & Varchar & 20 & $*$ \\
\hline Nama_Matkul & Varchar & 100 & \\
\hline Jumlah_Sks & Interger & 2 & \\
\hline Semester & Interger & 1 & \\
\hline Id_Prodi & Varchar & 20 & \\
\hline NIDN & Varchar & 20 & \\
\hline
\end{tabular}

Tabel 3. Tabel Ketua Prodi

\begin{tabular}{l|c|c|c|}
\hline \multicolumn{1}{c|}{ Field } & Type & Size & PrimaryKey \\
\hline Id_Prodi & Varchar & 2 & $*$ \\
\hline Prodi & Varchar & 50 & \\
\hline Ka_Prodi & Varchar & 50 & \\
\hline
\end{tabular}

\section{Diagram Konteks}

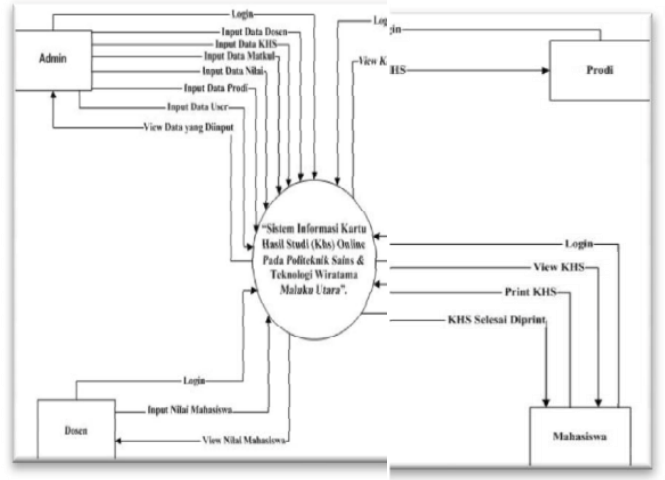

Gambar 2. Diagram Konteks

\section{DFD Level 1}

Diagram level 1 merupakan diagram uraian dari gamabaran sistem pada diagram konteks, berikut merupakan hasil rancangan diagram level 1

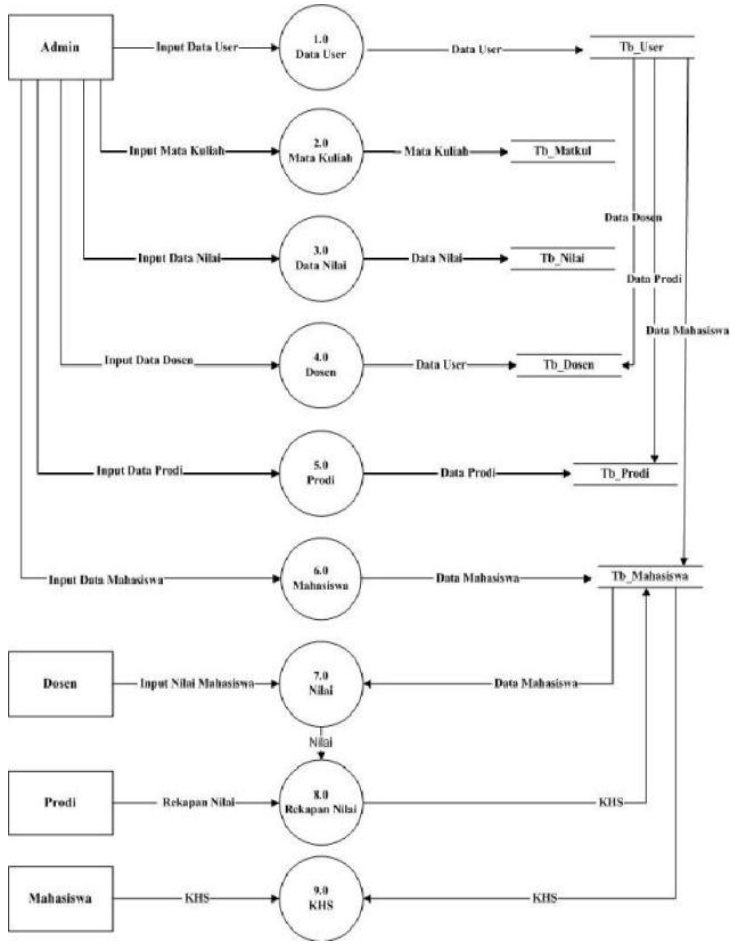

Gambar 3. DFD Level 1

\section{ERD Notasi}

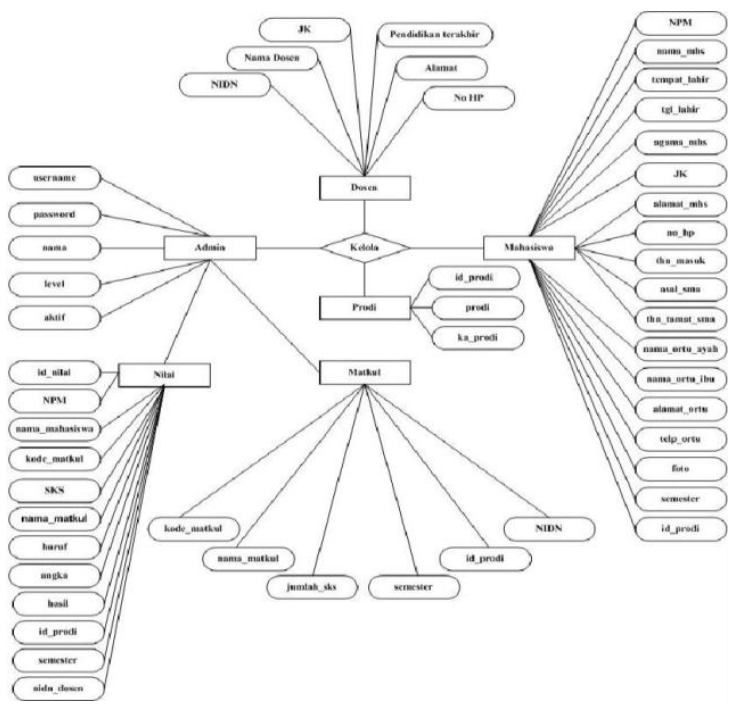

Gambar 4. ERD Notasi

\section{ERD Relasi Tabel}

Entity Relationship Diagram (ERD) Tabel merupakan uraian rancangan yang ada pada database yang dihubungkan 
secara relasi, berikut merupakan hasil ERD Tabel yang disajikan pada gambar dibawah ini:

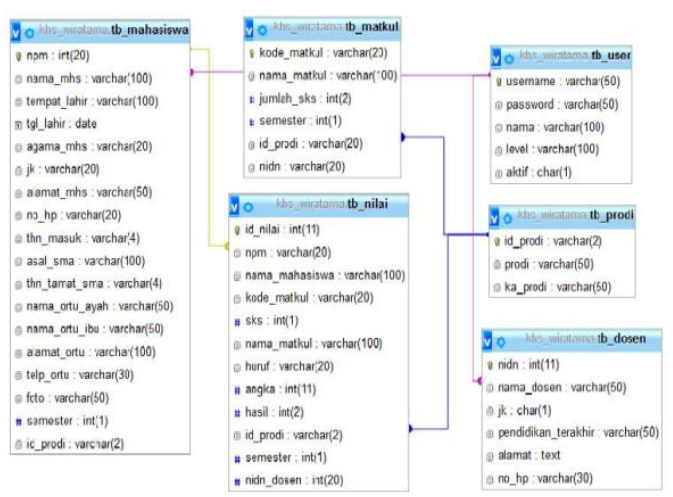

Gambar 5. Gambar Relasi tabel

\section{IMPLEMENTASI DAN PEMBAHASAN}

\section{Form Login}

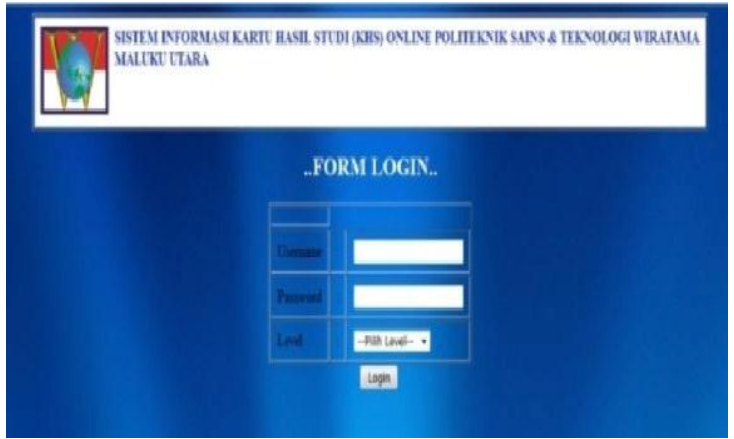

Gambar 6. Gambar Form Login

\section{Form Kelola Data Dosen}

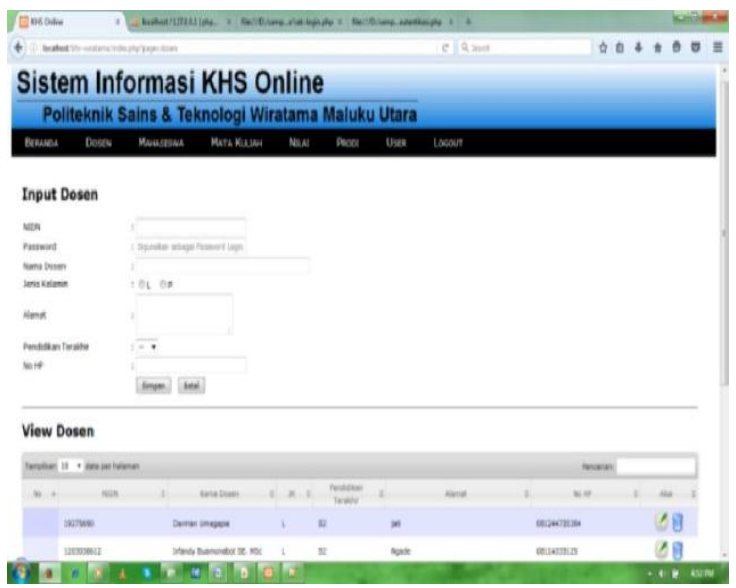

Gambar 7. Gambar Form Data Dosen

\section{Form Data Mahasiswa}

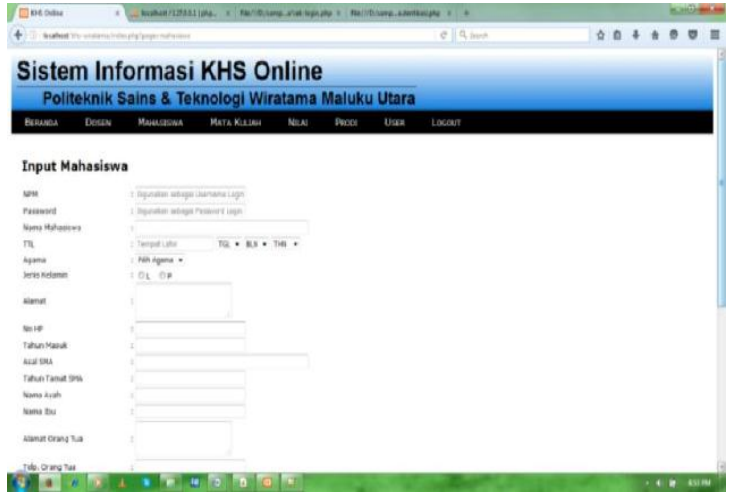

Gambar 8. Gambar Form Data Mahasiswa

\section{Form Mata Kuliah}

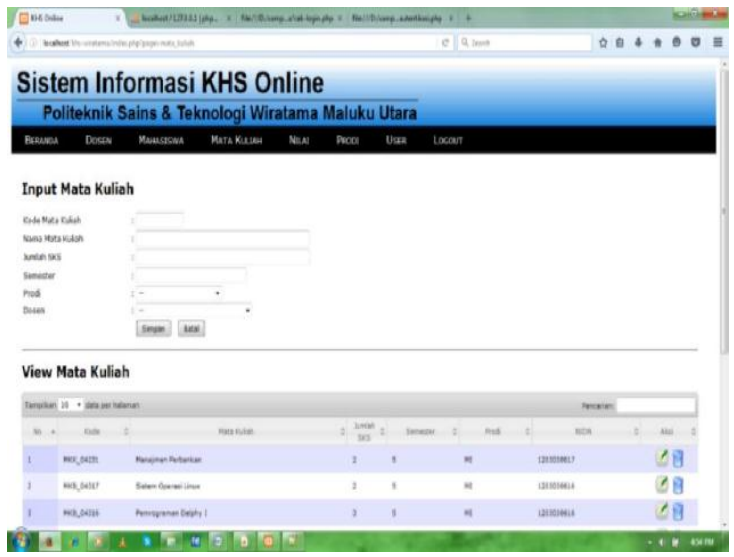

Gambar 9. Gambar Form Mata Kuliah

\section{Form KHS}

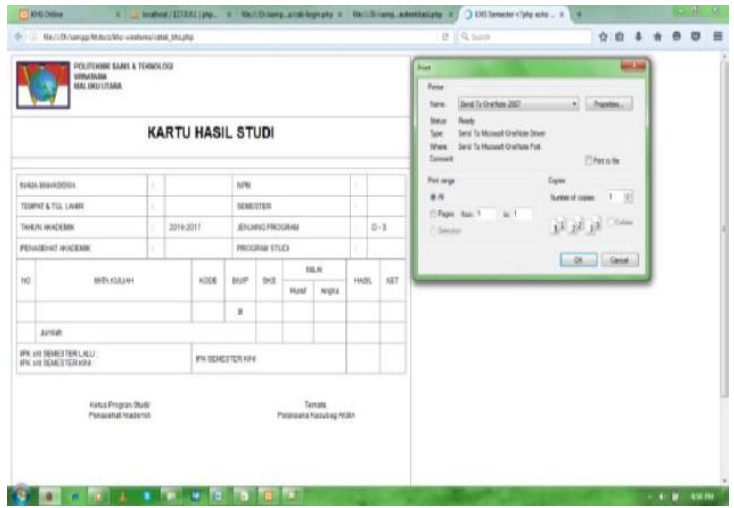

Gambar 10. Gambar Form KHS

\section{KESIMPULAN}

Dari hasil pengujian sistem bahwa sistem yang diuji dapat berjalan dengan baik dalam pengelolaan data-data mahasiswa, dosen dan nilai-nilai mahasiswa pada KHS diPoliteknik Sains \& Teknologi Wiratama Maluku Utara Ternate. Dengan adanya sistem informasi ini dapat mempermudah dalam 
pengelolaan data nilai serta meningkatkan pelayanan kampus. Begitu juga halnya dengan mahasiswa, dapat mengakses dan memperoleh kartu hasil studi (KHS) secara online pada sistem.

\section{Saran}

Disarankan Sistem Informasi Kartu Hasil Studi (KHS) Online ini dapat diterapkan untuk memperbaharui sistem yang lama pada Politeknik Sains \& Teknologi Wiratama Maluku Utara, dalam pengembangan berikut agar perlu mengabungkan beberapa sistem diantaranya KRS, KHS, Kuliah, serta pengisian Nilai Mahasiswa menjadi satu sistem terpadu agar admin dapat mengelola sistem sekaligus tanpa membuka link satu persatu

\section{DAFTAR PUSTAKA}

Fathansyah. 2012. Basis Data. Bandung, Penerbit: Informatika Bandung.

Jalaludin, Asep. 2010. Perancangan Sistem Informasi dan Kemahasiswaan (SIAK) Versi 1.0 menggunakan Visual Foxpro 6.0 Di Akademi manajemen informatika dan Komputer (AMIK) Wahana Mandiri Tanggerang: CSID Journal Vol 2 Nomor 3.

Jogiyanto, H. M, 2005. Analisa dan Desain. Yogyakarta : Penerbit Andi Offset.

Priyadi, Yudi. 2014. Kolaborasi SQl \& ERD Dalam Implementasi Database. Yogyakarta: Andi Offset.

Sugiyono. 2013. Metode Penelitian Pendidikan Pendekatan Kuantitatif, Kualitatif, dan $R \& D$. Bandung: Alfabeta.

Sutabri, T. 2012. Analisis Sistem Informasi. Yogyakarta: Andi Offset.

Hartono, Bambang. 2013. Sistem Informasi Manajemen Berbasis Komputer. Jakarta: Rineka Cipta.
Yakub. (2012). Pengantar Sistem informasi. Yogyakarta: Graha Ilmu

Tata Sutabri. 2012. Analisis Sistem Informasi. Andi. Yogyakarta

Brady, M., \& Loonam, J. (2010). Exploring the use of entityrelationship diagramming as a technique to support grounded theory inquiry. Bradford: Emerald Group

Zusnan Fahrudin, Eko Purwanto, Sistem Informasi Kartu Rencana Studi dan Kartu Hasil Studi Online, Jurnal Ilmiah Teknologi Informasi dan Komunikasi, Vol 3 Tahun 2012, ISSN: 2086-9436

Nur Asih. 2013. Pembuatan Kartu Hasil Studi (KHS) Berbasis Web Pada SMK Telekomunikasi Tunas Harapan Semarang: Naskah publikasi 